\title{
MUTIRÃO DA \\ HISTÓRIA: TEATRO, MEMÓRIA E APROPRIAÇÕES NO PRESENTE
}

\section{Natália Batista*}

Universidade de São Paulo

São Paulo - São Paulo - Brasil

Resenha de: XAVIER, Nelson \& BOAL, Augusto. Mutirão em Novo Sol. São Paulo: Expressão Popular, 2015.

A disciplina histórica tem observado o campo teatral com relativo distanciamento. Nos últimos anos as pesquisas têm aumentado gradativamente, mas ainda é possível perceber um olhar desconfiado para a temática. Entre as motivações para esta opção, constata-se a dificuldade de apreender a efemeridade do ato teatral, a carência de acervos e a necessidade de construir uma metodologia que contemple este novo objeto da história, mas velho na experiência humana. Entende-se que as problemáticas supracitadas não deveriam ser impeditivas para a análise do ato teatral em perspectiva

\footnotetext{
* Doutoranda pelo Programa de pós-graduação em História Social do Departamento de História da Faculdade de Filosofia, Letras e Ciências Humanas da Universidade de São Paulo. Mestre em História e Culturas Políticas pela Universidade Federal de Minas Gerais e pesquisadora do Núcleo de História Oral da mesma instituição. Autora do livro Nos palcos da História: "Liberdade, Liberdade". São Paulo: Editora Letra \& Voz, 2017. E-mail: nataliabatista@usp.br
} 
histórica. Deveriam servir antes como estímulo para a construção de novos olhares para a produção teatral.

A noção do "aqui e agora" do espetáculo, bem como a sua incapacidade de reprodução, poderiam justificar o afastamento dos historiadores dessa abordagem. No entanto é importante questionar: quais objetos da história podem ser reproduzíveis? A inserção de qualquer tema histórico no presente se dá a partir do trabalho do pesquisador que escolhe o tema, delimita o objeto, seleciona fontes e constrói uma metodologia útil para a sua pesquisa. Evidentemente, o estudo do teatro possui peculiaridades, mas sua matéria humana é a mesma de qualquer processo histórico. Ao pesquisar o teatro é preciso agir como o ogro da lenda descrito por Marc Bloch: "Onde fareja carne humana, sabe que ali está a sua caça" ${ }^{11}$, mesmo quando o odor humano lhe parece distante.

O ato teatral enquanto encenação se esvai no momento dos aplausos finais. No entanto, de acordo com Batista, o teatro "continua existindo na memória coletiva dos que o fizeram, o assistiram e da sociedade que o cercava. Ele persiste no tempo através de rastros, sinais, documentos e fragmentos de memória" ${ }^{2}$. Tomando por base essa perspectiva, o resultado obtido com a publicação Mutirão em Novo Sol é consistente, pois articula o texto da peça, escrito por Nelson Xavier, o contexto histórico de sua produção, a pesquisa teórica, a análise das diferentes encenações, a documentação de época, depoimentos dos participantes da montagem, além de suas apropriações no presente. A articulação das diferentes perspectivas contribui para fazer do teatro um objeto plenamente histórico, a partir do momento em que reconstrói aspectos do contexto que o produziu e insere a cultura como elemento facilitador da compreensão de aspectos político-sociais do Brasil dos anos 1960.

O livro Mutirão em Novo Sol foi publicado no ano de 2015, fruto da parceria entre a editora Expressão Popular e do LITS [Laboratório de Investigação em Teatro e Sociedade]. O LITS é um grupo de pesquisa vinculado ao Departamento de Artes Cênicas da Escola de Comunicações e Artes da Universidade de São Paulo. Seu objetivo é "conectar trabalhos de pesquisa acadêmica e artística e, assim, gerar reflexões críticas sobre as interações entre formas teatrais, projetos de modernização e situações produtivas da vida cultural ${ }^{3 "}$.

\footnotetext{
1 BLOCH, Marc. Apologia da história ou O ofício do historiador. Rio de Janeiro: Jorge Zahar, 2001, p.54.

2 BATISTA, Natália. Nos palcos da História: “Liberdade, Liberdade". São Paulo: Editora Letra E Voz, 2017, p.77. XAVIER, Nelson $\mathcal{E}$ BOAL, Augusto. Mutirão em Novo Sol. São Paulo: Expressão Popular, 2015, p.191.
} 
A publicação da obra analisada dialoga efetivamente com os pressupostos sugeridos pelo coletivo.

Trata-se de um trabalho posicionado politicamente e que percebe a importância de desvelar uma obra desconhecida do grande público, contextualizar sua produção e interpretá-la a partir do contexto atual. De acordo com Iná Camargo, autora da orelha do livro, trata-se de um "resgate do outro lado da história" a partir do momento em que coloca em cena um texto que destaca a temática da reforma agrária, fazendo uma adaptação da rebelião conhecida como Arranca Capim, que ocorreu no interior de São Paulo.

A peça se passa na fictícia cidade de Novo Sol e o eixo na narrativa é o julgamento de Roque, um líder camponês. É possível observar um ir e vir no tempo, que perpassa a ação presente [o julgamento] e a reconstrução histórica [passado] da luta dos camponeses desde a sua chegada à Fazenda Cova das Antas e o acordo com Porfírio, dono da fazenda. Ele definia que após arar as terras os camponeses poderiam semeá-las. No entanto, no momento do plantio o latifundiário desfaz o acordo e tenta expulsar os trabalhadores para plantar capim e alimentar o gado. Diante da morosidade do poder judiciário para resolver a questão, os camponeses saqueiam o barracão da fazenda, além de arrancarem o capim plantado. Como forma de vingança, Porfírio manda matar Honório, um farmacêutico que tenta ajudar os camponeses na busca por justiça. Durante a peça vários personagens fingem prestar "solidariedade" aos trabalhadores, mas fica evidente o medo que possuem do latifundiário, uma espécie de coronel da região que controla a justiça, a igreja e a polícia, dentre outras instituições. Tentando encontrar alternativas, os camponeses se organizam para fundar a União [uma espécie de associação], motivação para que Roque seja acusado de subversão e agitação. No final da peça, ocorre um enfrentamento onde o líder camponês é condenado, mas pode ser liberado desde que convença os camponeses a parar o "arranca capim". Ele não aceita o acordo e explicita que a luta dos trabalhadores é mais forte que a individual e eles continuarão na luta mesmo sem a sua presença.

O texto da peça foi escrito por Nelson Xavier em 1961. Contou ainda com a participação de Augusto Boal, principalmente na elaboração das falas do Coronel Porfírio. Ele foi produzido após uma conversa com Jôfre Corrêa Neto, inspiração para o personagem Roque. O líder camponês havia acabado de ser liberado da prisão e concedeu uma entrevista no Teatro de Arena de São Paulo, contando como se deu a resistência na Fazenda Santa Fé do Sul e os pormenores do que ficou conhecido como o Arranca Capim. A partir desta experiência real e da narrativa de Jôfre, a dramaturgia foi sendo construída. Ela não teve como objetivo fazer uma adaptação do fato histórico, mas 
se apropriar dele para construir um texto que dialogasse com o contexto político nacional, já que a luta pela terra perpassou e ainda perpassa todos os estados brasileiros.

De acordo com a Nota Introdutória de Sérgio Carvalho o texto tem grande importância na dramaturgia brasileira, tendo em vista que "inaugura uma sequência de peças de temática camponesa produzidas antes do golpe de 1964, influenciando o cinema novo do período; assume o ponto de vista dos explorados de modo radical, utiliza-se de elementos épicos como poucas vezes no teatro político no Brasil" ${ }^{\prime 4}$. Sua circulação enquanto obra teatral encenada permitiu que as perspectivas apresentadas no texto pudessem chegar ao público formal, mas também ao público que inspirou sua dramaturgia: os camponeses. Talvez pela necessidade de compreender o texto a partir da experiência teatral concreta é que o livro buscou analisar estas diferentes perspectivas.

A publicação é composta por alguns eixos centrais: o texto da peça e sua avaliação crítica, além das diferentes propostas de encenação. No primeiro eixo, o texto, é possível perceber a intervenção do coletivo que compara as suas duas edições e o recria a partir de seu cotejamento. São utilizadas muitas notas de rodapé para orientar o leitor sobre as escolhas dos editores do texto. Nesse sentido, trata-se de um trabalho que deixa claro as suas intervenções e propostas de interpretação do texto enquanto documento. Assume-se, nesta reflexão, o texto como documento histórico, pois se considera que sua análise pode descortinar aspectos da sociedade brasileira no que tange à compreensão do teatro [enquanto produto cultural] e da política [enquanto prática social].

No que diz respeito aos artigos complementares da publicação é possível perceber que eles descortinam aspectos que vão do texto à encenação. Alguns são teórico-analíticos e outros memorialísticos, o que lhes confere singularidade ao articular a teoria e a memória. É uma escolha interessante mostrar tanto a produção intelectual em torno do texto quanto as interpretações dos sujeitos sobre eles próprios e a encenação.

A publicação contou com muitas entrevistas. Elas foram utilizadas tanto nos textos de análise, produzidos por pesquisadores, quanto na compreensão da memória dos sujeitos que participaram de alguma etapa do texto ou da montagem de Mutirão do Novo Sol. Por vezes, percebem-se diferentes narrativas para o mesmo evento vindas de sujeitos diversos, o que dá à

\footnotetext{
${ }_{4}$ XAVIER, Nelson $\&$ BOAL, Augusto. Mutirão em Novo Sol. São Paulo: Expressão Popular, 2015, p.7.
} 
publicação um caráter polifônico, além da dimensão ambígua de qualquer experiência histórica.

O livro é dividido em três partes: Soma-se a "Depoimentos" e "Imagens $e$ Canções" [blocos que fecham o livro] uma primeira parte não nominada, que contempla o texto teatral e uma de análise teórico-histórica mais densa. Nela está contida a Nota Introdutória de Sérgio Carvalho, que faz uma breve apresentação da história da escrita da peça, assim como sua importância na dramaturgia nacional. A Apresentação, assinada pelo autor Nelson Xavier, narra o processo de construção da peça e a importância do testemunho de Jôfre, que permitiu alcançar minimamente o ideal de um teatro que dialogasse de forma mais efetiva com o povo, como desejava alguns integrantes do Teatro de Arena. Ela é seguida do texto dramatúrgico completo e de uma Avaliação, escrita também por Nelson Xavier quando assistiu a adaptação da peça feita em 2012, no Encontro Unitário dos Trabalhadores, Trabalhadoras e Povos do Campo, das Águas e Florestas. O autor faz um paralelo sobre a sociedade brasileira no contexto da escrita e quando foi reencenada, em 2012. Para ele, a peça expressa a sua geração, ou a forma como ele viveu e pensou as emoções de sua geração.

O artigo Jôfre, Roque e a Guerra do Capim, de Clifford Andrew Welch, apresenta dados históricos oriundos de documentação e entrevistas realizadas a partir da metodologia da história oral. O autor contextualiza a vida de Jôfre, narra a sua trajetória e tece comparações entre a história dita oficial e a narrativa construída na peça. Ele compara o nome dos personagens reais e fictícios, à ascensão de Jôfre e à força devastadora do Estado na mediação da questão. O texto permite compreender a peça e as opções estéticas de seus autores, assim como apontar as possibilidades do estudo do teatro no campo da disciplina histórica. Ao final ele menciona que apesar das diferenças com o caso real, a peça iluminava aspectos da luta pela terra no Brasil, tais como a miséria dos camponeses, o poder latifundiário, a corrupção das instituições do Estado e a única alternativa do campesinato, a auto-organização.

Nos textos que seguem são apresentados três diferentes encenações da peça ainda no período anterior ao golpe civil-militar. São eles Mutirão no CPC Paulista, de Sara Mello Neiva, que analisa a montagem realizada com a direção de Gianfrancesco Guarnieri; Julgamento no MCP do Recife, de Paula Autran, que investiga a inovação instituída pela peça no que tange à imediata recepção pelos camponeses; e Rebelião do CPC da Bahia, de Mariana Soutto Mayor, que narra a relação dos artistas de teatro, cinema e música na produção da montagem baiana.

Além da peça em si e de sua análise, o livro contribui também para descortinar outro aspecto importante da cultura brasileira deste período: a pro- 
dução do CPC [Centro Popular de Cultura] em pelo menos dois estados: São Paulo e Bahia. Ao se investigar as montagens do CPC fora do Rio de Janeiro é possível observar a força dos CPCs e o seu importante papel na discussão das questões nacionais através da cultura. O mesmo ocorreu com o MCP [Movimento de Cultura Popular], de Recife, que começa a se articular com outros movimentos de base inseridos nesse contexto. A publicação segue o percurso da peça por diferentes estados e permite visualizar as singularidades das encenações. O último tópico da primeira parte é a Cronologia, que faz uma articulação entre a história e a memória, já que foi inserida exatamente entre os textos de análise teórico-histórica e os depoimentos.

A segunda parte, intitulada Depoimentos, consistiu na apresentação de entrevistas editadas, que foram realizadas para o livro ou produzidas em contextos anteriores. Para cada depoimento foi selecionado um título que enunciasse a temática central das narrativas e orientasse o leitor em seu percurso literário. São eles: Peripécias da Montagem, de Chico de Assis; Aprendizado no Arena, de Ricardo Ohtake; Público Camponês, de Juca de Oliveira; Ligas Camponesas e MCP; de Moema Cavalcanti; Trabalho de Cultura Popular, de Luiz Mendonça; Dramaturgia no MCP, de Ilva Niño; e Rebelião em Salvador, de Orlando Senna.

Alguns depoimentos foram coletados especificamente para a publicação e outros produzidos em diferentes contextos. Um ponto alto da utilização dos depoimentos é localizar o leitor, explicitando quando as entrevistas foram produzidas, por quem e com quais objetivos. Tais informações são fundamentais para entender as construções dos sujeitos no tempo e o caráter transitório da própria memória. Para Ulpiano “a memória é uma construção social, é formação de imagem necessária para os processos de constituição e reforço da identidade individual, coletiva e nacional. Não se confunde com a História, que é forma intelectual de conhecimento, operação cognitiva ${ }^{5 "}$. Nesse sentido, a memória, quando não é problematizada, cria tensões com a História e isso é perceptível em alguns momentos do livro. Seria interessante que os depoimentos fossem acompanhados de uma análise histórica ou de uma breve discussão sobre o papel da memória na composição do livro. Em determinados momentos História e memória se confundem e podem causar inquietações em um leitor que desconhece a temática. De qualquer modo, não tira o mérito da iniciativa de colocar na mesmo publicação diferentes pontos de vista sobre a mesma experiência histórica, a peça.

5 MENESES, Ulpiano T. Bezerra de. A História, cativa da memória: para um mapeamento da memória no campo das Ciências Sociais. In: Rev. Inst. Est. Bras, São Paulo, n. 34, 1992, p.22. 
Outra informação perceptível nos textos acadêmicos e depoimentos é a modificação do horizonte de expectativa dos sujeitos após o golpe civilmilitar. Para além dos artistas envolvidos com as manifestações de cunho engajado, foram perseguidos também os camponeses que tinham qualquer tipo de atuação política. Sendo a peça uma tentativa de elo entre artistas e camponeses, quase todos os envolvidos tiveram seus rumos modificados não só na perspectiva artística, mas também na política.

Na terceira parte, intitulada Imagens e Canções, discutiu-se a questão musical em Partituras das Canções, de Paulinho Tó; a análise da documentação de época a partir do texto Imagens de um processo, de Érika Rocha e Paulo Fávari; e o Posfácio, de Rafael Villas Bôas, que descreve o processo de "redescoberta" do texto, o contexto em que as edições foram cedidas pelo autor e sua eficácia simbólica ao ser trabalhado com os integrantes do MST [Movimento dos Trabalhadores Rurais Sem Terra].

O livro pode ser entendido como um alentado esforço de pesquisa, edição, publicação e divulgação de uma importante obra dramatúrgica. Ele pode ser pensado no sentido de um grande mutirão da história, onde pesquisadores, historiadores, atores e sujeitos se unem para a realização de uma obra coletiva, preocupada em discutir as experiências do passado com vistas a transformar o presente. Se a história caminha com parcimônia na análise do campo teatral, a publicação Mutirão em Novo Sol apresenta interessantes desdobramentos que podem inspirar os historiadores e fomentar novas possibilidades de estudo do teatro no campo da disciplina histórica.

\section{Bibliografia}

BATISTA, Natália. Nos palcos da História: "Liberdade, Liberdade”. São Paulo: Editora Letra $\mathcal{E}$ Voz, 2017.

BLOCH, Marc. Apologia da história ou O ofício do historiador. Rio de Janeiro: Jorge Zahar, 2001.

MENESES, Ulpiano T. Bezerra de. A História, cativa da memória: para um mapeamento da memória no campo das Ciências Sociais. In: Rev. Inst. Est. Bras, São Paulo, n. 34, 1992, p. 09-24.

XAVIER, Nelson $\mathcal{E}$ BOAL, Augusto. Mutirão em Novo Sol. São Paulo: Expressão Popular, 2015. 